bundle is transected, and while the auricle is fibrillatinga fact which demonstrates that all auricalar impulses to it are impeded by such a procedure. As a consequence the ventricle assumes its own spontaneous slow and regular rhythm. Partial heart-block is readily induced by asphyxia, and, in conjunction with Dr. Mathison, I have utilized this faot to show that when a condition of heartblock is present, the production of auricular flbrillation, while disturbing the regularity of the ventricular contrac. tions, fails to bring about the marked increase of rate which usually accompanies its onset in the normal animal. It may be similarly shown that when the anricle is fibrillating the production of partial heart-block reduces the rate of the ventricular responses (Figs. 5 and 6).

The clinical condition, auricular fibrillation, has been seen in association with heart-block of several grades; with partial heart-block in the curves of Dr. G. A. Gibson, ${ }^{6}$ by Dr. Mackenzie, ${ }^{6}$ and myself; in all these cases the ventricular rate was slow; and a case of auricular fibrillation has been recently reported in which complete heart-block in an epileptio and syphilitic subject was probably present. ${ }^{7}$ In this case the ventricle best regularly at a rate of approximately 30 per minute.

We see, therefore, that the known ways in which the ventricular action may be retarded, whether the fibrillation is clinical or experimental, are of one type; in all instances heart-block is either probable or proved. What more natural than to suspect that digitalis acts in a similar manner when it produces ventricular slowing in the clinical condition? For digitalis has been found to induce heart. block experimentally, and clinically a similar action has been described by Mackenzie, ${ }^{9}$ and has been fully substantiated by a number of more recent workers.

The case for which I plead-that digitalis slowing is a result of heart-block when the auricle is fibrillating-is very materially strengthened when the following facts are considered: The type of case in which, with the normal or co-ordinate contraction of the auricle present, heart.block is readily provoked by digitalis administration, is the advanced rheumatic heart, and a fortiori the heart affected by mitral stenosis. It is a striking fact that of all cases of clinical anricular fibrillation, those which are of rhoumatic origin, and a fortiori those affected by mitral stenosis, show the characteristic slowing of digitalis to most advantage. This is the type of case in which digitalis acts in so magic a fashion, and in which the rate of the ventricle is set by the dosage employed; it is the type of case in which the ventricalar rhythm may be sometimes reduced to regularity, and in which the rate may be reduced to that consistent with a true ventricular rhythm.

On the other hand, there is the type of patient in whom no reaction ensues apon the exhibition of the drug. Now Mackenzie has shown that digitalis produces heart.block in those patients in whom a previous defect of conduction exists. The proposition I pat to you is a parallel one, namely, that the ventricle is retarded in auricular fibrillation by digitalis when there is a pre-existing damage of the junctional tissues, a damage which is frequentily demonstrable in cases of rheumatic heart affection.*

The complete evidence in support of this proposition will require time for its collection. We require observations upon patients in the early stages of the affection. It is requisite that it be demonstrated that a large proportion of the cases which react to digitalis had a deficiency of auriculo-ventricular conduction before the onset of fibrilla. tion. I can offer the facts in regard to three cases ${ }^{10}$ only at the present time. In these three cases the heart. rhythm was observed before the onset of fibrillation, or during the intervals of rest between attacks. The cases were thoroughly tested with digitalis during the stage of fibrillation. Two cases, in which no previous defect of conduction could be demonstrated, failed to show a trace of reaction to the drag. The third case in which deficiency of conduction was clearly established reacted repeatedly and in the most typical manner.

The view suggested, therefore, is that the ventricular rate is retarded in clinical auricular fibrillation by the action of digitalis upon the junctional tissues, the functions of which are already in a depressed state; and this view

*The view that digitalis acts by the production of beart-block was originally put forward in the BRITISH M P.DICAL JoURNAL Of Novem is put forward, together with an indication of the direction from which the evidence will come, which, if favour able, should convert what may be now regarded as a proposition into a well-established conclusion.

1 Lewis, Heart. 1909-10, i, 306. 2 Lewis, ibid., 1910-11, ii, 23. 8 Cushny and Edmunds, Amer. Journ. Med. Sci.. 1907, cxxxii. 66. 4 Frederica. Archiv. Internat. d. Physiol.o 1904-5, ii, 281. E Gibson, BRIMTBH MRDICAI JoURNAI, 1906, ii, 1113. 'Taokenzie, Heart, 1909-10. 1, 23. T' Lewis, ibid. 1909, i. 349; and Lewis and Mack, Quart. Journ. of Med., 1909-10, iii, 273. MEdicat, Journ. Exper, Med., 1905, i, 587. 10 Lewis, Heart, 1909-10, i, 306 (c8ses 2. Mo, and 11).

\section{VARIATIONS OF THE FERMENTATION} PROPERTIES OF THE B. TYPHOSUS. *

By W. J. PENFOLD, M.B., B.Hy., M.R.C.S., BRITISH MEDICAL ASBOCIATION SOHOLAR. (From the Lister Institute, London.)

\section{Lactose.}

Dr. Twort has shown that the B. typhosus can be made to ferment lactose-peptone water. He found that two years' growth on lactose-peptone water was necessary to produce this atrain. I have examined this new variety and find: (1) It is a genuine $B$.typhosus. (2) On plating on lactose it always gives rise to mixed plates of ferment. ing and non-fermenting colonies. Subcalture of fermenting colonies on lactose plates gives again a mixture of fermenting and non-fermenting colonies, so that the character is always tending to diseppear and requires constant growth on lactose for its retention.

If the atavistic non-fermenting colonies are retrained on lactose-agar slopes, after a variable number of subcultures they take on the fermenting power again. In this process of training, when the efficient fermenting strain is arising they show papillae-formation on the lactose, the papillae being very large and acid in reaction 8 s indicated by neutral red.

I have attempted the complete training of a large number of strains myself, and have only got one to the stage of very slightly fermenting lactose-peptone water in two dajs. I have not jet got red colonies out of it. This has required sixteen monthly suboultures.

\section{Dulcite.}

I have shown + that $B$. typhosus requires abont ten days to produce acidity in dulcite-peptone water. The period can be readily shortened to one day by one to three subcaltures on dulcite media at monthly intervals. Normal $B$. typhosus produces neutral or alkaline colonies on duloite agar. About the fifth dey, in one-third of the strains papilliform projections arise on the colonies, which become acid in a dey or two. Subcultures from these papillae give rise to fermenting colonies. Other strains of $B$. typhosus give papillae about eight to ten dajs after inoculation. These do not acquire an acid reaction. Occasionally strains do not show papillae on this medium.

Plating on dulcite agar daily from dulcite broths of B. typhosus shows the history of the variation. It usually takes two to ten days to produce fermenting elements on dulcite agar. Then, some time later, all the non.fermenting elements are killed off suddenly, and the broth contains only fermenting elements.

This new fermenting character tends to recede after its firgt selection, bat if continuous growth on dulcite is nnder. taken for two to three months, the character remains permanent. A strain so trained and selected about nine months ago gave on plating out within the last few days pure plates of fermenting colonies.

Thus apparently two years' growth on lactose selects out a strain acting similarly to a dulcite strain selected in about a week. How long will a pare permanent lactose strain require for its selection?

\section{Arabinose.}

$B$. typhosus does not ferment arabinose on neutral red arabinose agar plates and ferments arabinose peptone water very slowly and irregularly. After three months'

A paper read in the Bection of Bacteriology at the annual meeting of the British Medical Association, London, July 29th, 1910. 
training on arabinose peptone water, I have succeeded in getting this fermentation in arabinose broths to occur overnight. On plating out at this stage, the plates may consist entirely of pure fermenters. I have not yet tested this character for permanency. All the three above-mentioned varieties agglatinate with a typhoid serum readily.

\section{Glycerine.}

Glycerine provides an illustration of another type of variation. Normal $B$. typhosus ferments glycerine. All the recently isolated strains examined, I have found on plating on glycerine agar to be pure fermenters. Three old laboratory strains I examined have shown, however, mixed plates of fermenters and non.fermenters. Sub culture of each of these types has given rise to pure races of the respective varieties. After five subcultures on peptone water, these still retained their pure character. Probably this negative veriation is due to the laboratory cultare, and the loss occurs so slowly as not to show itself in the same red strain after so few as five subcultures.

It is rather remarkable that pure fermenting strains inoculated on glycerine peptone water take about three to four days to produce full acidity and eight months' training does not quicken this period. After one day the litmus is completely decolorized by the fermenting strains, but on agitation it regains its colour and only the faintest trace of acidity is seen.

I have not yet. tested whether the non-fermenting strains can be readily retrained, but in glycerine litmus peptone water they do not show any signs of acidity after two or three weeks. Both strains give all the other fermentation and agglutination tests of $B$. typhosus. The agglutinability of the non-fermenting strain is, however, somewhat impaired.

Isodulcite.

R. Müller has drawn attention to papillae-formation by $B$. typhosus on isodulcite. This I have observed in all the strains I have examined. Subcultare from these, gives rise to colonies no longer able to form these papillae, but growing mach more luxuriantly on isodulcite-agar. I found that subculture of these new colonies on peptone water thirteen times, failed to restore the papillae-forming power in any of the four strains so tested, This is apparentiy a mutation. Growth of $B$. typhosus on isodulcite broth frequently does not produce acidity though it may do so as early as one week. By 1 to 3 subcultures at monthly intervals, all strains I have tested give acjdity in forty. eight hours.

The above five variants of $B$. typhosus agreed with the normal type in all their other fermentation and general properties, that is, the fermentation variations seemed to arise without any concomitant qualitative variations in respect of other fermentation and general characters.

\section{Unsuccessful Variations.}

I have grown $B$. typhosus (12 straing) in peptone water, containing formates, for about eight months, in order to get. a gas-forming strain, but so far without results. Adonite, erythrite, saccharose, amygdalin, and salicin have all failed to select out special strains, though they were ased for about nine months in each case.

Do the above-described variations undermine the value of sugar tests? I think not. Th3y show, however, their dimitations-namely, that laboratory cultare can vary them. Short laboratory caltare on particular carbo. hydrates will change the type, and evidently, in the case of glyoerine, subculture on ordinary nutrient agar will do it atter a long period. Cultures fresh from the blood or excretions of typhoid patients, however, show an almost absolute conformity to type in respect of fermentation characters, whereas the agglutination tests, when applied to freshly-isolated strains, not infrequently break down. It seems to me, therefore, that, in the recognition of these organisms, fresh from the body, the fermentation characters take a pre.eminent position.

In conclusion, I should like to put in a plea for the value of the fermentation tests in elucidating the laws of bacterial variation. They are easily applied, and if once anderstood would probably explain many of the most difficult problems in connexion with virulence and other propertios of micro-organisms.

\section{A CASE OF DIAPHRAGMATIC HERNIA IN AN ADULT.}

BY

ERNEST RINGROSE, M.D.DURH., L.R.C.P., M.IR.C.S., HONORARY SURGEON, NEWARK HOSPITAL.

MaNY cases of congenital deficiency in the diaphragm, chiefly left-sided, in infants have been collected both in this country and abroad, but the instances of the subjects having lived to adult life are extremely rare, and therefore I feel that no apology is required for recording this case.

M. L., aged 26 years, married three years, no ohildren. She was a seven months child, had acute rheumatism thirteen years ago, was always highly neurotic; was a school teacher before marriage, and had been passed as sound bv the medica examiner. She never suffered from digestive troubles. She was always very thin and was in the habit of lacing rather tightiy.

In August, 1909, she was examined for uterine and bladder trouble and found to have marked anteflexion; nothing abnormal was found on palpation of the abdomen.

The patient became pregnant in November. she had during her early months of prègnancy.

On 3 r 1910 , and had "dn " 1910, she complained of leellig sick, and had vomited.

On June lst she was seen by me; her face was very flushed, the respirations 44 ; pulse 144 , regular, low tension; temperatare $100.4^{\circ}$. The heart's apex best was in the fifth space, a little internal to the nipple line; the first and second sounds were normal. The peroussion note over the front of the left side of the thorax was dull up to the second rib; above that it was hyper-resonsnt. The breath sounds were weak except at th third space, where they were bronchial. On the left side at the back there was dullness on peroussion, weak breath sounds and diminighed vocal tremitus up to the angle of the sospula; above that the perongsion note 78 clesr and the breath sound brial pero andible anywhere over brof the left sid of the the left costal margin. The patient was constantly eructatin about half an ounce of clear yellowish fluid; the bowels acted well. The abdomen

about seven months. June 2nd. The patient had a restless night; the pain went away, but the eructations continued, the left back was quite dull on peroussion, the bresth sounds absent, and the heart's apex beat was in the epigastrium towards the right; aspiration was decided upon, but about 6 p.m. the child was born without any labour pains or warning; the placenta came away normally, and there was very little hemorrhage. During the kneading of the uterus a large mass was felt in the left iliac and lumbar region; this wes thought to be an ovarian cyst, but on exsminstion ; rainam nothing could be made ont, and the uterus was tion per vaginam comfortable, so it quite der a that night.

On June 3rd my colleague, Dr. Hine, saw the patient with me; the pulse was 144, the respirations 44 , temperature $100^{\circ}$; the heart's apex beat was then found to be again in the nfth space, just to the left of the sternum; slight janndioe was noticed. The mass in the left side of the abdomen was freely movable and easily examined, and diagnosed

The bowels aoted well, the stool being like putty.

June 4th. The patient was markedly jaundioed, the liver edge was felt two fingerbreadths below the costal margin, the eructations continued, the fluid now being quite black, the lest thorax remained the same, but the heart's apex beat was again to the right edge of the sternum. The thorax was aspirated in the fifth space at the posterior axillary border and $6 \mathrm{oz}$. of black fluid came sway. The patient became cyanosed and the pulse very small and weak; it was decided not to prooeed with the very small and weak; it was decided not to prooeed with the aspiration. The patient continued to vomit small quantities of black fluid throughout the night; she had intense pain on the
left side by the costal margin for an hour before death, which left side by the costal mar.
took place the next day.

Post-mortem Examination-The autopey was made twenty hours after death, at which Dr. Hine assisted me. The uterus was healthy and no larger than is natural after labour; the appendages were normal. The spleen was found five fingerbreadths below the costal margin and approsching the midale line; it was slightly enlarged. The stomach was enormousty distended and partially filled with black fluid, about 3 quarts in all; the fundus was situated in the thorax, as far up as the second rib; the pylorus was in its uenel position, there being an hourglass constriction where the portion of the stomach passed through the diephragm owing to a partial strangulation. In addition the whole stomach was rotated on its long axis; the great carvature was uppermost, the posterior sunface boing antexine and 